\title{
Oral health among white, black, and Mexican-American elders: an examination of edentulism and dental caries
}

\author{
Bei Wu, PhD'; Jersey Liang, PhD²; Brenda L. Plassman, $\mathrm{PhD}^{3}$; R. Corey Remle, PhD'; Lina Bai, MS \\ 1 School of Nursing and Global Health Institute, Duke University, Durham, NC \\ 2 School of Public Health, University of Michigan, Ann Arbor, Ml \\ 3 Department of Psychiatry and Behavioral Sciences, Duke University Medical Center, Durham, NC \\ 4 Department of Sociology, Wake Forest University, Winston-Salem, NC \\ 5 Department of Epidemiology, University of Pittsburgh, Pittsburgh, PA
}

\section{Keywords}

older adults; oral health disparity; blacks; Mexican-Americans.

\section{Correspondence \\ Dr. Bei Wu, School of Nursing and Global Health Institute, Duke University, 307 Trent Drive, Durham, NC 27710. Tel.: 919-685-7534; e-mail: bei.wu@duke.edu. Bei Wu is with the School of Nursing and Global Health Institute, Duke University. Jersey Liang is with the School of Public Health, University of Michigan. Brenda L. Plassman is with the Department of Psychiatry and Behavioral Sciences, Duke University Medical Center. \\ R. Corey Remle is with the Department of Sociology, Wake Forest University. Lina Bai is with the Department of Epidemiology, University of Pittsburgh.}

Received: 11/24/2009; accepted: 4/22/2011

doi: 10.1111/j.1752-7325.2011.00273.x

\begin{abstract}
Objectives: To examine racial/ethnic disparities in oral health among older Americans.

Methods: Differences in frequency of edentulism and number of decayed, missing, and filled teeth were assessed in 2,679 non-Hispanic white, 742 non-Hispanic black, and 934 Mexican-American individuals aged 60 and older from the National Health and Nutrition Examination Survey (1999-2004).

Results: Controlling for potential confounding variables, blacks and MexicanAmericans had significantly higher numbers of decayed teeth but fewer numbers of filled teeth than whites. Although blacks had a lower likelihood of being edentulous than whites, dentate blacks had a higher number of missing teeth. Compared with whites, Mexican-Americans were less likely to be edentulous, and dentate MexicanAmericans had fewer missing teeth. Our study also showed that blacks and MexicanAmericans had less frequent dental checkups than whites.

Conclusions: Oral health disparities are persistent across racial/ethnic groups for older Americans despite the fact that the differences between groups typically diminish when socioeconomic, health-related, and behavioral factors are considered in the models. Our study suggests that reducing racial/ethnic oral health disparities requires multiple clinical approaches.
\end{abstract}

While an increasing number of studies have examined oral health disparities across race/ethnicity in the United States, a limited number of such studies have been conducted for older adults. Policy makers, public health officials, and other healthcare providers need to better understand how social factors, along with medical conditions, may contribute to racial/ethnic disparities in oral health with the demographic transition to a more diverse older population in the United States (1).

A report from the Surgeon General (2) noted ongoing racial/ethnic disparities in oral health across all ages, but it stressed the need for research to explain these differences. A first step toward explaining the disparities is to know how oral health differs between the groups. Some studies have reported that older Hispanic and black Americans have more missing teeth and decayed teeth than their white counterparts (3-7). Using the National Health and Nutrition Examination
Survey (NHANES 1999-2004), a recent report found that both blacks and Mexican-Americans have a higher prevalence of untreated tooth decay and missing teeth than whites. However, Mexican-American adults were least likely to have lost all teeth compared with whites and African-Americans (3). In fact, a few studies have suggested that older black adults have even worse oral health than Hispanics (7-10). Many of the previous studies used small convenience samples or only individuals with low socioeconomic status (SES); some were not able to compare the three racial/ethnic groups in the same sample, and some did not evaluate potential confounders that may help to explain differences among the racial/ethnic groups.

The present study addresses many of the methodological issues noted above by comparing racial/ethnic differences in oral health among community-dwelling non-Hispanic white, non-Hispanic black, and Mexican-American older adults 
aged 60 and above using NHANES (1999-2004). This study provides four key innovative refinements on earlier work. First, we compare whites, blacks, and Mexican-Americans, and use a nationally representative sample of older adults when most previous studies compared only blacks and whites using small community-based samples of various cohorts. Second, we include edentulous and dentate individuals using a two-stage analytic approach. The first stage includes both edentulous and dentate respondents in the sample, and the second stage includes only dentate respondents. Third, we investigate a comprehensive array of potential factors that may, in combination, explain the relationship between race/ ethnicity and oral health: SES, social support, health behaviors, chronic medical conditions, functional limitations, and dental care use. Fourth, we examine multiple clinical indicators of oral health [i.e., complete edentulism, missing teeth (partial edentulism), decayed teeth, and filled teeth] to examine racial/ethnic differences in multiple dimensions of dental caries while controlling for important covariates that could contribute to the oral health disparities. It is important to examine these domains individually because of the distinctive oral health problems and treatments that each domain reflects.

To address gaps in the literature and to extend previous research findings, we propose three hypotheses. The first two hypotheses are based on the report from Dye et al. (3). First, black and Mexican-American elders have more decayed teeth than their white counterparts among dentate individuals. Corollary to this, minority elders may have fewer filled teeth because of a lower number of teeth present and a higher number of untreated decayed teeth compared with whites. Minority older adults may also have a lower rate of dental care utilization than whites. Second, relative to whites, blacks are more likely to be edentulous, and dentate blacks have more missing teeth. However, in comparison with whites, MexicanAmericans have a lower likelihood of being edentulous, and dentate Mexican-Americans have fewer missing teeth. Finally, racial/ethnic differences in oral health are confounded by SES, social support, chronic medical conditions and functional limitations, health behaviors, and dental care utilization.

\section{Methods}

\section{Study design}

This study used the NHANES (1999-2004), a populationbased survey designed to collect information on the health and nutrition of the US population. The NHANES used a stratified, multistage, clustered sampling design to obtain a representative sample of the noninstitutionalized civilian US population. Data were collected during in-home interviews, and dental and health examinations conducted in mobile examination centers. The in-home interviews were conducted by trained interviewers in either English or Spanish (11). For the current study, we combined three waves of data collected over 6 years (1999-2000, 2001-02, and 2003-04) for a total of 4,984 individuals aged 60 and above. The study sample excluded 125 respondents who were from other minority groups, 351 respondents with missing dental examination information, and 153 non-Mexican Hispanics. The final sample was 4,355 individuals aged 60 and above who received dental health examinations and completed the in-home interviews. Among them, 3,307 had one or more teeth, and 1,048 were edentulous. The sample consisted of 2,679 non-Hispanic whites, 742 non-Hispanic blacks, and 934 Mexican-Americans.

\section{Measures}

Oral examinations were based on a maximum of 28 teeth. Third molars were excluded because of their frequent extraction. Oral health status was measured in several ways: edentulous versus dentate $(1=$ individuals without any natural teeth, $0=$ otherwise), the number of decayed teeth, missing teeth, and filled teeth. In each case, a higher number indicates poorer oral health status or a higher level of dental treatment received.

Race/ethnicity was measured using dichotomous variables for whites, blacks, and Mexican-Americans. We included age (measured in years), gender (female $=1)$, a categorical variable representing level of education $(1=$ less than high school, 2 = high school, and 3 = some college or above), and a dummy variable for any insurance (e.g., private insurance or Medicaid) that covers any part of dental care ( $1=$ having coverage). Income was measured by the family poverty income ratio, which was calculated as the ratio of family income versus the poverty threshold produced annually by the US Census Bureau. The variable was treated as a continuous variable, and a higher ratio reflects a higher level of income. Three dimensions of social support were measured: marital status ( $0=$ not married, $1=$ married $)$, number of close friends or relatives, and self-perception as to whether someone else would provide financial support, if needed.

Health status was defined in several ways: the diagnosis of one or more health conditions and functional impairment. Respondents were asked if a doctor had ever diagnosed them with diabetes, high blood pressure, heart disease, stroke, or lung disease (i.e., asthma, emphysema, or chronic bronchitis). Each condition was treated as a dichotomous variable. Functional impairment was defined as self-reported limitations related to daily activities. Activities of daily living (ADLs) included eating, dressing, walking, and getting in and out of bed. Instrumental ADLs (IADLs) included managing money, doing household chores, preparing meals, and shopping. The scale of ADL and IADL limitations was created by 
adding one point for each of the eight activities. Three health behaviors were included: smoking (current smoker $=1$ ), alcohol use, and level of physical activity. Alcohol use was categorized as nondrinkers (the reference group), light or moderate drinkers (between 12 drinks in the past 12 months and less than 2 drinks per day), and heavy drinkers (two drinks per day in the previous 12 months). Level of physical activity was measured dichotomously as either little to no activity (“0”) or moderate to high level of activity (" 1 ”).

Dental care utilization was measured as the time since the last regular dental checkup. In the 1999-2002 interviews, the following questions were asked: "during the past three years, have you been to the dentist for routine checkup or cleaning?" and "during the past three years, how often have you gone to the dentist for routine check-ups or cleanings?" In the 2003-04 interviews, only one question was asked: "how long has it been since you had your teeth cleaned by a dentist or dental hygienist?" We combined the responses to create an ordinal variable where $1=$ the last dental visit was more than 3 years ago (including those who never had a regular dental visit or cleaning); 2 = occurred within the past 3 years; and $3=$ within the past year.

\section{Analysis}

We used STATA (StataCorp, College Station, TX, USA) for data analyses. Analysis of variance (ANOVA) and generalized linear model (GLM) procedures were performed to compare sample characteristics across the three groups. A two-stage analytical procedure was used in the study. The first stage included both dentate and edentulous respondents in the analyses. The second stage included only dentate individuals.

Multivariate analysis procedures were used to test the racial/ethnic differences in oral health while controlling for many confounders that may explain the differences among the racial/ethnic groups. In order to test the hypothesis that racial/ethnic differences in oral health are confounded by covariates such as SES, social support, chronic medical conditions and functional limitations, health behaviors, and dental care utilization, a hierarchical block design was used in multivariate analyses. The first model included race/ethnicity. The second model added sociodemographic characteristics. The third model added social support and health behaviors, and the fourth model added health status and regular dental checkups. We used the method identified by Clogg and colleagues (12) to compare regression coefficients between nested models for black and Mexican-American respondents in model 1 (including only race/ethnicity) with those in model 4 (including all other covariates) for each of the four oral health outcomes.

STAT SVY procedures were performed to take into account the weights provided in the data set yielding unbiased standard error estimates (13). SVY: LOGISTIC was used for logis- tic regression models on the dependent variable of edentulism. SVY: NBREG was used to test general linear regression models with negative binomial distributions on three dependent variables among dentate individuals: decayed teeth, missing teeth, and filled teeth. To minimize the loss of cases because of missing values, we used all our analysis variables to impute a range of plausible values for missing cases. We derived parameter estimates and their standard errors by averaging across five imputations and by adjusting for their variance (14). These data sets were analyzed using STATA procedures (described above) along with the STATA MI to aggregate results to obtain proper standard errors accounting for additional variation across imputed data sets (15). We constructed fully specified models that include all variables using both unimputed data and imputed data to examine the effects for robustness. No substantial differences were found between the two sets of models.

We next excluded the variables that were not significant at the 0.10 level in the full specified models across four oral health outcomes. Two measures of social support, number of close friends or relatives, and whether someone else would provide financial support, if needed, were not significant in the models; therefore, these two variables were excluded in the final models.

We took steps to address multicollinearity by checking the correlations between independent variables prior to inclusion in the models. On the basis of criteria of 2.5 for the variance inflation factor and 0.4 for tolerance $(16,17)$, the models were not affected by multicollinearity.

\section{Results}

Table 1 shows characteristics of study participants by race/ ethnicity. All these variables were included in the multivariate analysis unless otherwise specified in the analysis plan (see above). ANOVA results indicated that black, MexicanAmericans, and whites differed significantly in all characteristics except for gender and the rate of heavy drinking. GLMs were used to further test oral health differences across the three groups. The descriptive results showed that in comparison with whites and Mexican-Americans, blacks had a significantly higher number of missing teeth, with an average of 3.5 more than whites $(P<0.05)$ and 4.3 more than MexicanAmericans $(P<0.01)$. Blacks also had significantly higher rates of edentulism (28.6 percent) than both whites (24.5 percent) and Mexican-Americans (18.1 percent). However, Mexican-Americans had the lowest rate of edentulism (18.06 percent) among the three groups but the highest number of decayed teeth by comparison. Additionally, minorities had many fewer filled teeth than whites, particularly blacks who had 2.7 filled teeth compared with 7.3 for whites and 4.7 for Mexican-Americans. 
Table 1 Descriptive Statistics of Oral Health and Key Covariates by Race/Ethnicity (Weighted)

\begin{tabular}{|c|c|c|c|c|c|}
\hline Variable & $\begin{array}{l}\text { Total sample } \\
(n=4,355) \\
\text { Mean (SD)/\% }\end{array}$ & $\begin{array}{l}\text { Non-Hispanic } \\
\text { white }(n=2,679) \\
\text { Mean (SD)/\% }\end{array}$ & $\begin{array}{l}\text { Non-Hispanic } \\
\text { black }(n=742) \\
\text { Mean }(\mathrm{SD}) / \%\end{array}$ & $\begin{array}{l}\text { Mexican-American } \\
(n=934) \\
\text { Mean (SD)/\% }\end{array}$ & $\begin{array}{l}\text { ANOVA } \\
\text { (F-value) }\end{array}$ \\
\hline \multicolumn{6}{|l|}{ Sociodemographics } \\
\hline Age (range 60-85) & $71.2(0.20)$ & $71.4(0.23)$ & $69.9(0.34)$ & $68.7(0.22)$ & $169.4 * * *$ \\
\hline Female & 55.8 & 55.5 & 60.0 & 53.6 & 1.1 \\
\hline Education & & & & & $352.0 * * *$ \\
\hline Less than high school & 28.8 & 24.4 & 55.0 & 73.2 & \\
\hline High school & 29.7 & 31.5 & 17.2 & 10.1 & \\
\hline More than high school & 42.5 & 44.1 & 26.8 & 16.7 & \\
\hline Dental coverage & 33.7 & 31.6 & 53.6 & 35.3 & $78.0^{\star \star *}$ \\
\hline Poverty income ratio (range 0-5) & $2.8(0.07)$ & $2.9(0.08)$ & $2.2(0.06)$ & $1.9(0.04)$ & $147.2 * * *$ \\
\hline \multicolumn{6}{|l|}{ Social support } \\
\hline Anyone to help with financial support & 77.8 & 78.1 & 76.9 & 72.7 & $3.5^{*}$ \\
\hline Number of close friends (range $0-3.93$ ) & $1.9(0.02)$ & $2.00(0.02)$ & $1.5(0.03)$ & $1.6(0.02)$ & $102.9 * * *$ \\
\hline Married & 60.2 & 62.2 & 38.0 & 63.0 & $56.1 * * *$ \\
\hline \multicolumn{6}{|l|}{ Health status } \\
\hline Diabetes & 13.3 & 11.9 & 23.3 & 23.5 & $55.7^{* * *}$ \\
\hline High blood pressure & 53.5 & 51.9 & 71.1 & 49.6 & $42.4^{* * *}$ \\
\hline Heart disease & 22.1 & 22.6 & 18.9 & 16.3 & $15.6^{* * *}$ \\
\hline Stroke & 7.4 & 7.2 & 10.0 & 7.1 & 2.3 \\
\hline Lung disease & 18.3 & 18.8 & 15.9 & 10.6 & $12.8^{* * *}$ \\
\hline ADL and IADL score (range 0-8) & $1.1(0.05)$ & $1.1(0.05)$ & $1.5(0.08)$ & $1.5(0.07)$ & $10.2^{* * *}$ \\
\hline \multicolumn{6}{|l|}{ Health behaviors } \\
\hline Light moderate drinker & 32.8 & 34.3 & 21.4 & 24.6 & $25.4^{* \star *}$ \\
\hline Heavy drinker & 3.3 & 3.5 & 2.3 & 2.3 & 1.0 \\
\hline Current smokers & 11.5 & 11.0 & 15.9 & 13.0 & $12.8^{* * *}$ \\
\hline Moderate physical activity or more & 49.9 & 52.1 & 33.6 & 36.4 & $53.4 * * *$ \\
\hline \multicolumn{6}{|l|}{ Dental care utilization } \\
\hline Last regular dental checkup & & & & & $24.4^{* * *}$ \\
\hline More than 3 years & 19.0 & 17.9 & 27.5 & 28.8 & \\
\hline $1-3$ years & 14.2 & 13.4 & 23.5 & 18.7 & \\
\hline Within 1 year & 66.8 & 68.7 & 49.0 & 52.6 & \\
\hline \multicolumn{6}{|l|}{ Oral health status } \\
\hline Edentulous & 24.6 & 24.5 & 28.6 & 18.1 & $18.6^{* * *}$ \\
\hline Decayed teeth (range 0-28) & $0.4(0.04)$ & $0.3(0.03)$ & $0.8(0.08)$ & $1.0(0.05)$ & $66.7^{* * *}$ \\
\hline Missing teeth (range 0-28) & $13.00(0.38)$ & $12.7(0.43)$ & $16.3(0.36)$ & $12.0(0.23)$ & $40.8^{* * *}$ \\
\hline Filled teeth (range 0-28) & $9.00(0.21)$ & $7.3(0.30)$ & $2.7(0.17)$ & $4.7(0.21)$ & $351.7^{* * *}$ \\
\hline
\end{tabular}

* $P<0.05, * * * P<0.001$.

SD, standard deviation; ANOVA, analysis of variance; ADL, activities of daily living; IADL, instrumental activities of daily living.

With regard to other characteristics, blacks and MexicanAmericans were younger than whites, and a higher proportion of the respondents reported having insurance that covers some dental care. However, they had a lower income and less frequent dental checkups than whites. In addition, a higher proportion of blacks reported having systemic diseases than whites and Mexicans.

Table 2 presents the logistic regression analysis determining the odds of edentulism. Model 1 demonstrated that Mexican-Americans were 32 percent less likely than whites to be edentulous, while the odds for edentulism among blacks were not significantly greater than for whites. However, in the fully specified model (model 4 ), both blacks [odds ratio $(\mathrm{OR})=0.63$, 95 percent confidence interval $(\mathrm{CI})=0.47$,
0.84] and Mexican-Americans ( $\mathrm{OR}=0.29,95$ percent $\mathrm{CI}=0.21,0.41)$ were less likely to have lost all of their teeth compared with whites. Edentulism was associated with being older, smoking, having fewer years of education and less income, having had a stroke, and less ADL/IADL impairment. However, maintaining one's natural teeth was associated with light to moderate alcohol use, moderate or greater physical activity, and more frequent dental checkups.

Table 3 presents negative binomial regression analyses of the associations among race/ethnicity, possible confounding variables, and missing teeth for dentate participants. In model 1, race/ethnic differences were significantly and positively associated with missing teeth for blacks but not for Mexican-Americans. When all confounding variables were 
Table 2 Logistic Regression Analysis on Edentulism

\begin{tabular}{|c|c|c|c|c|}
\hline Variable & $\begin{array}{l}\text { Model } 1 \\
\text { OR }(95 \% \mathrm{Cl})\end{array}$ & $\begin{array}{l}\text { Model } 2 \\
\text { OR }(95 \% \mathrm{CI})\end{array}$ & $\begin{array}{l}\text { Model } 3 \\
\text { OR }(95 \% \mathrm{CI})\end{array}$ & $\begin{array}{l}\text { Model } 4 \\
\text { OR }(95 \% \mathrm{Cl})\end{array}$ \\
\hline \multicolumn{5}{|l|}{ Sociodemographics } \\
\hline Black & $1.23(0.99,1.54)$ & $0.80(0.61,1.06)$ & $0.72(0.54,0.96)^{*}$ & $0.63(0.47,0.84)^{\star *}$ \\
\hline Mexican & $0.68(0.49,0.95)^{\star}$ & $0.33(0.23,0.46)^{\star * *}$ & $0.32(0.24,0.45) * * *$ & $0.29(0.21,0.41) * * *$ \\
\hline Age & & $1.02(1.01,1.03)^{* *}$ & $1.02(1.01,1.04)^{\star * *}$ & $1.03(1.02,1.04)^{* * *}$ \\
\hline Female & & $1.01(0.88,1.16)$ & $0.92(0.79,1.07)$ & $1.10(0.92,1.32)$ \\
\hline Education & & $0.52(0.45,0.61) * * *$ & $0.56(0.47,0.66) * * *$ & $0.61(0.53,0.70) * * *$ \\
\hline Poverty income ratio & & $0.74(0.68,0.82) * * *$ & $0.80(0.73,0.89) * * *$ & $0.85(0.77,0.95) * *$ \\
\hline Dental coverage & & $0.85(0.68,1.07)$ & $0.86(0.68,1.10)$ & $0.97(0.74,1.29)$ \\
\hline \multicolumn{5}{|l|}{ Social support } \\
\hline Married & & & $0.90(0.74,1.09)$ & $0.96(0.80,1.16)$ \\
\hline \multicolumn{5}{|l|}{ Health behaviors } \\
\hline Light/moderate drinker & & & $0.61(0.50,0.74) * * *$ & $0.73(0.59,0.91) * *$ \\
\hline Heavy drinker & & & $0.67(0.40,1.10)$ & $0.64(0.37,1.11)$ \\
\hline Current smoker & & & $2.44(1.77,3.35) * * *$ & $2.05(1.44,2.91) * * *$ \\
\hline Moderate physical activity or more & & & $0.61(0.49,0.74) * * *$ & $0.63(0.50,0.81) * * *$ \\
\hline \multicolumn{5}{|l|}{ Health status } \\
\hline Diabetes & & & & $1.18(0.89,1.56)$ \\
\hline High blood pressure & & & & $1.03(0.82,1.30)$ \\
\hline Heart disease & & & & $1.16(0.87,1.55)$ \\
\hline Stroke & & & & $1.48(1.02,2.17)^{\star}$ \\
\hline Lung diseases & & & & $1.12(0.84,1.48)$ \\
\hline ADL and IADL score & & & & $0.94(0.90,0.98)^{* *}$ \\
\hline \multicolumn{5}{|l|}{ Dental care utilization } \\
\hline Regular dental checkup & & & & $0.46(0.38,0.55) * * *$ \\
\hline ROC & 0.55 & 0.72 & 0.74 & 0.78 \\
\hline
\end{tabular}

* $P<0.05, * * P<0.01, * * * P<0.001$.

Model 1: ethnicity only; model 2: adding sociodemographic characteristics; model 3: adding variables on social support and health behaviors; and model 4: adding health status and dental care utilization.

OR, odds ratio; CI, confidence interval; ADL, activities of daily living; IADL, instrumental activities of daily living; ROC, Receiver Operating Characteristic.

controlled (model 4), the difference for blacks was reduced (0.21) but remained significant. In other words, by transforming the log function of "missing teeth" counts into multiplicative effects, dentate blacks had 1.23 times more missing teeth than whites. For Mexican-Americans, race/ethnic differences became significant but were negatively associated with missing teeth. Compared with whites, the difference was 0.23 lower for Mexican-Americans, which means that Mexican-Americans had 20 percent fewer missing teeth.

Factors such as being older, lower levels of education and income, smoking, and being diabetic were related to having a higher number of missing teeth, while being married, moderate or vigorous physical activity, and more frequent dental checkups were associated with retaining more natural teeth.

Table 4 demonstrates that race/ethnicity was significantly associated with decayed teeth in model 1 . When controlling for all other variables, blacks and Mexican-Americans still retained a significantly greater predicted number of decayed teeth compared with whites in the final model (model 4), but the log value decreased to 0.65 and 0.45 , respectively. Blacks and Mexican-Americans had 1.92 and 1.57 times more decayed teeth than whites. Men had more decayed teeth than women, and lower education levels and lower income were also associated with a higher number of decayed teeth. Smoking was associated with a greater number of decayed teeth, while light or moderate alcohol use was inversely associated with the outcome. Regular dental checkups contributed to improved oral health within the sample.

In Table 5, compared with whites, the significant differences in the logs of counts of filled teeth was 0.93 lower for blacks and 0.73 for Mexican-Americans in model 1 . In the fully specified model, blacks and Mexican-Americans retained a significantly lower predicted number of filled teeth compared with whites, but the log values decreased to 0.65 and 0.35 , respectively, which means that blacks and MexicanAmericans had 0.52 and 0.70 times fewer filled teeth than whites. Respondents who were female, married, and had higher levels of education and income had a greater number of filled teeth. In addition, light or moderate alcohol use and moderate physical activity were positively associated with the number of filled teeth, while smoking and having diabetes were inversely associated with filled teeth. Further, regular dental checkups contributed to the increased number of filled teeth. 
Table 3 Negative Binomial Regression Results on Number of Missing Teeth among Dentate Elders

\begin{tabular}{|c|c|c|c|c|}
\hline & $\begin{array}{l}\text { Model } 1 \\
b(S E)\end{array}$ & $\begin{array}{l}\text { Model } 2 \\
b(S E)\end{array}$ & $\begin{array}{l}\text { Model } 3 \\
\text { b (SE) }\end{array}$ & $\begin{array}{l}\text { Model } 4 \\
b(S E)\end{array}$ \\
\hline \multicolumn{5}{|l|}{ Sociodemographics } \\
\hline Black & $0.40(0.05) * * *$ & $0.29(0.05) * * *$ & $0.24(0.05) * * \star$ & $0.21(0.05) * * *$ \\
\hline Mexican & $0.08(0.06)$ & $-0.21(0.06)^{* \star *}$ & $-0.21(0.05)^{\star \star *}$ & $-0.23(0.05) * * *$ \\
\hline Age & & $0.01(0.00)^{* * *}$ & $0.01(0.00)^{* *}$ & $0.01(0.00)^{\star * *}$ \\
\hline Female & & $-0.07(0.04)$ & $-0.13(0.04) * *$ & $-0.08(0.05)$ \\
\hline Education & & $-0.26(0.02) * * *$ & $-0.25(0.02)^{\star * *}$ & $-0.23(0.02) * * *$ \\
\hline Poverty income ratio & & $-0.13(0.02)^{* * *}$ & $-0.09(0.02)^{\star * *}$ & $-0.08(0.02) * * *$ \\
\hline Dental coverage & & $-0.05(0.04)$ & $-0.03(0.04)$ & $-0.01(0.04)$ \\
\hline \multicolumn{5}{|l|}{ Social support } \\
\hline Married & & & $-0.17(0.05)^{* *}$ & $-0.15(0.04) * *$ \\
\hline \multicolumn{5}{|l|}{ Health behaviors } \\
\hline Light/moderate drinker & & & $-0.20(0.04)^{* * *}$ & $-0.15(0.04) * * *$ \\
\hline Heavy drinker & & & $-0.07(0.10)$ & $-0.03(0.09)$ \\
\hline Current smoker & & & $0.37(0.08)^{* * *}$ & $0.36(0.08) * * *$ \\
\hline Moderate physical activity or more & & & $-0.08(0.04)$ & $-0.06(0.04)$ \\
\hline \multicolumn{5}{|l|}{ Health status } \\
\hline Diabetes & & & & $0.20(0.06)^{* *}$ \\
\hline High blood pressure & & & & $0.02(0.04)$ \\
\hline Heart disease & & & & $0.07(0.06)$ \\
\hline Stroke & & & & $-0.02(0.09)$ \\
\hline Lung diseases & & & & $0.00(0.04)$ \\
\hline ADL and IADL score & & & & $0.00(0.01)$ \\
\hline \multicolumn{5}{|l|}{ Dental care utilization } \\
\hline Regular dental checkup & & & & $-0.15(0.02) * * *$ \\
\hline
\end{tabular}

** $P<0.01, * * * P<0.001$.

Model 1: ethnicity only; model 2: adding sociodemographic characteristics; model 3: adding variables on social support and health behaviors; and model 4: adding health status and dental care utilization.

SE, standard error; ADL, activities of daily living; IADL, instrumental activities of daily living.

\section{Discussion}

The findings support our first hypothesis that blacks and Mexican-Americans had significantly higher numbers of decayed teeth but fewer numbers of filled teeth than whites, even controlling for many confounding variables. The results partially supported the second hypothesis that blacks were more likely to have a higher number of missing teeth than whites; nonetheless, different from the hypothesis, they were less likely to be edentulous. Compared with whites, MexicanAmericans were less likely to be edentulous, and dentate respondents were also less likely to lose their natural teeth. The results also supported the third hypothesis that racial/ ethnic differences were confounded by other health-related and social factors that often differ by race/ethnicity. Overall, oral health disparities across racial/ethnic groups persisted even after controlling for other covariates.

The comparison of the regression coefficients for black and Mexican-American respondents in model 1 (including only race/ethnicity) with those in model 4 (including all other covariates) showed that racial/ethnic variations in oral health were confounded by a number of variables. In particular, blacks and Mexican-Americans were less likely to be edentu- lous than whites after controlling for SES, health behavior, dental care utilization, and other covariates. Some anecdotal evidence has suggested that minorities are concerned about saving their teeth for esthetic reasons (6). We surmise that the level of concern may be greater for those with relatively higher SES and social support. However, the value of saving natural teeth could also be compromised by the general lack of dental care among minority elders. Further studies are warranted regarding the tension between esthetic concerns and ability to access dental care services.

One study examined trends of edentulism over the past 30 years and found trends of improvement for low- and highSES black adults (18). The authors also suggested that for the population reporting regular dental care utilization and/or nonsmoking behaviors, socioeconomic disparities in edentulism were reduced. Consistent with their findings, our study indicated that healthier behaviors (i.e., nonsmoking, light/ moderate drinking, and physical activity) and regular dental visits may contribute to a lower rate of edentulism for minority elders compared with whites. Therefore, health programs and services designed to improve health behaviors and access to regular dental visits are important in reducing racial/ ethnic disparities (19). 
Table 4 Negative Binomial Regression Results on Number of Decayed Teeth among Dentate Elders

\begin{tabular}{|c|c|c|c|c|}
\hline & $\begin{array}{l}\text { Model } 1 \\
b(S E)\end{array}$ & $\begin{array}{l}\text { Model } 2 \\
b(S E)\end{array}$ & $\begin{array}{l}\text { Model } 3 \\
\text { b (SE) }\end{array}$ & $\begin{array}{l}\text { Model } 4 \\
b(S E)\end{array}$ \\
\hline \multicolumn{5}{|l|}{ Sociodemographics } \\
\hline Black & $1.08(0.15) * * *$ & $0.81(0.15)^{* * *}$ & $0.71(0.14)^{* * *}$ & $0.65(0.14) * * *$ \\
\hline Mexican & $1.04(0.16) * * *$ & $0.51(0.16)^{\star *}$ & $0.51(0.15)^{* *}$ & $0.45(0.15)^{\star *}$ \\
\hline Age & & $0.00(0.01)$ & $-0.01(0.01)$ & $0.00(0.01)$ \\
\hline Female & & $-0.62(0.12)^{* * *}$ & $-0.78(0.11)^{\star * *}$ & $-0.70(0.10)^{* * *}$ \\
\hline Education & & $-0.37(0.09) * \star *$ & $-0.29(0.08) * \star$ & $-0.23(0.09)^{\star}$ \\
\hline Poverty income ratio & & $-0.32(0.04) * * *$ & $-0.25(0.04) * * *$ & $-0.22(0.04) * * *$ \\
\hline Dental coverage & & $-0.09(0.17)$ & $-0.07(0.16)$ & $0.04(0.14)$ \\
\hline \multicolumn{5}{|l|}{ Social support } \\
\hline Married & & & $-0.16(0.18)$ & $-0.14(0.18)$ \\
\hline \multicolumn{5}{|l|}{ Health behaviors } \\
\hline Light/moderate drinker & & & $-0.65(0.14)^{\star * *}$ & $-0.55(0.15)^{* *}$ \\
\hline Heavy drinker & & & $-0.14(0.30)$ & $-0.31(0.30)$ \\
\hline Current smoker & & & $0.31(0.15)^{*}$ & $0.19(0.15)$ \\
\hline Moderate physical activity or more & & & $-0.41(0.11)^{\star *}$ & $-0.28(0.13)^{\star}$ \\
\hline \multicolumn{5}{|l|}{ Health status } \\
\hline Diabetes & & & & $0.11(0.19)$ \\
\hline High blood pressure & & & & $-0.08(0.12)$ \\
\hline Heart disease & & & & $-0.15(0.15)$ \\
\hline Stroke & & & & $-0.20(0.14)$ \\
\hline Lung diseases & & & & $0.01(0.15)$ \\
\hline ADL and IADL score & & & & $0.03(0.04)$ \\
\hline \multicolumn{5}{|l|}{ Dental care utilization } \\
\hline Regular dental checkup & & & & $-0.51(0.06)^{* * *}$ \\
\hline
\end{tabular}

In this study, racial/ethnic differences remained even after controlling for all other covariates. The findings reflect a historical lack of access to dental care for racial/ethnic minorities $(20,21)$. Evidence suggests that dental insurance coverage, regular dental visits, and oral health are strongly associated. In our study, while a higher proportion of racial/ ethnic minority groups - blacks in particular - had dental insurance coverage, they also had more decayed teeth, a lower number of filled teeth, and less frequent regular dental visits. Further analyses were conducted to examine the association between race/ethnicity and dental care utilization. However, the relationship between race/ethnicity and regular dental care was not significant once SES and other covariates were included (results not shown). While the literature suggests that elders with Medicaid have a higher utilization of general medical services (e.g., physician visits and hospital use), they often demonstrate a low use of dental services, particularly preventative services, given that Medicaid often only covers tooth extractions in many states. Racial/ethnic disparities in dental care could be partially explained by differential treatment as a result of limited dental coverage and inadequate participation of dentists in the Medicaid program (22). Our study did not find a signifi- cant association between dental coverage and oral health. The general lack of effect of the dental coverage in our study suggests that the two distinct types of insurance (i.e., private dental insurance and Medicaid) may impact oral health differently given that these two insurances offer different types of dental coverage and tend to provide benefits to individuals with different population characteristics.

Oral health is associated with individual's SES (10). This association is often explained by the fact that individuals with higher income and a higher level of education are more likely than others to seek preventive dental care, have healthy behaviors, or have access to dental services when they are needed. Our study confirmed the finding that individuals with higher level of education and income had better oral health outcomes, even controlling for the factors on health behaviors and preventive dental care. We suspect that the results may arise from unmeasured differences in the quality of dental care currently received. Another possibility is that our cross-sectional data do not capture the cumulative effects of access to dental care throughout the life course.

The observed disparities may also reflect current or lifetime dietary habits, and current or lifetime smoking habits and other negative health behaviors among minorities. 
Table 5 Negative Binomial Regression Results on Number of Filled Teeth among Dentate Elders

\begin{tabular}{|c|c|c|c|c|}
\hline & $\begin{array}{l}\text { Model } 1 \\
\text { b (SE) }\end{array}$ & $\begin{array}{l}\text { Model } 2 \\
\text { b (SE) }\end{array}$ & $\begin{array}{l}\text { Model } 3 \\
\text { b (SE) }\end{array}$ & $\begin{array}{l}\text { Model } 4 \\
\text { b (SE) }\end{array}$ \\
\hline \multicolumn{5}{|l|}{ Sociodemographics } \\
\hline Black & $-0.93(0.07)^{\star * *}$ & $-0.75(0.06)^{* * *}$ & $-0.70(0.07)^{* * *}$ & $-0.65(0.06)^{\star * *}$ \\
\hline Mexican & $-0.73(0.10)^{* * *}$ & $-0.39(0.10)^{* * *}$ & $-0.38(0.10)^{* *}$ & $-0.35(0.10)^{* *}$ \\
\hline Age & & $0.00(0.00)$ & $0.00(0.00)^{*}$ & $0.00(0.00)$ \\
\hline Female & & $0.20(0.03)^{* * *}$ & $0.25(0.03)^{* * *}$ & $0.20(0.03)^{* * *}$ \\
\hline Education & & $0.27(0.03)^{* * *}$ & $0.26(0.03)^{\star * *}$ & $0.24(0.03)^{* * *}$ \\
\hline Poverty income ratio & & $0.12(0.01)^{* * *}$ & $0.09(0.01)^{* * *}$ & $0.08(0.01)^{* * *}$ \\
\hline Dental coverage & & $0.02(0.03)$ & $0.02(0.03)$ & $0.00(0.03)$ \\
\hline \multicolumn{5}{|l|}{ Social support } \\
\hline Married & & & $0.15(0.03)^{* * *}$ & $0.13(0.03)^{* * *}$ \\
\hline \multicolumn{5}{|l|}{ Health behaviors } \\
\hline Light/moderate drinker & & & $0.10(0.03)^{\star *}$ & $0.06(0.03)$ \\
\hline Heavy drinker & & & $0.06(0.07)$ & $0.04(0.06)$ \\
\hline Current smoker & & & $-0.27(0.07)^{* * *}$ & $-0.23(0.06)^{* *}$ \\
\hline Moderate physical activity or more & & & $0.12(0.03)^{* *}$ & $0.09(0.03)^{*}$ \\
\hline \multicolumn{5}{|l|}{ Health status } \\
\hline Diabetes & & & & $-0.14(0.06)^{*}$ \\
\hline High blood pressure & & & & $0.01(0.03)$ \\
\hline Heart disease & & & & $-0.02(0.04)$ \\
\hline Stroke & & & & $0.01(0.07)$ \\
\hline Lung diseases & & & & $-0.04(0.03)$ \\
\hline ADL and IADL score & & & & $0.01(0.01)$ \\
\hline \multicolumn{5}{|l|}{ Dental care utilization } \\
\hline Regular dental checkup & & & & $0.26(0.02)^{* * *}$ \\
\hline
\end{tabular}

Additionally, the results presented in this study could reflect unmeasured racial/ethnic differences in oral health beliefs and oral hygiene practice, and a lack of dental knowledge. Other researchers have suggested that clinicians should be aware that minorities may be less likely than whites to believe in the benefits of preventative practices (23).

Some systemic diseases such as diabetes and stroke were risk factors for edentulism and missing teeth. In order to improve minority elders' oral health, medical and public health professionals should ensure that oral health messages are included in literature and information is disseminated about diabetes and recommendations for diabetes care. While other studies found that cardiovascular diseases and lung disease may be associated with oral health $(24,25)$, our study did not find such associations. Our results could be due to limitations of self-reported health information and the lack of information on duration and severity of the conditions (11). Alternately, associations between some systemic medical conditions and oral health could be mediated by other variables included in our study such as SES and health behaviors, as previous studies have suggested $(9,10)$.

In our multivariate analyses, the relationship between the ADL/IADL score and edentulism appeared to be negative, which means that individuals with a higher ADL/IADL score were less likely to be edentulous. This finding is counterintuitive and is somewhat different from previously published studies (26). We further investigated these results. In a univariate logistic regression model that included only the variable ADL/IADL limitation score, higher levels of ADL/ IADL limitations were associated with a higher frequency of edentulism. This relationship remained significant even when sociodemographic and social support variables were added to the model. However, the relationship reversed direction, that is, higher ADL/IADL limitation scores were associated with lower rates of edentulism, when health status and medical condition variables were added to the model. In summary, ADL/IADL impairment is positively correlated with edentulism, whereas its net effect becomes negative when other health status measures are controlled. We suspect that the relationship is an artifact and that there is a complex relationship among oral health, chronic conditions, and functional status.

Research that includes all Hispanics, Asian-Americans, and Native Americans is also needed to examine racial/ethnic differences more fully. Hispanics, including Central/South American origin individuals, Cubans, Puerto Ricans, and 
Mexican-Americans, are culturally diverse with different customs, values, migration patterns, and SES (27). In this regard, factors such as acculturation and age at immigration may have important implications for oral health in middle and later life.

In conclusion, our study shows that oral health disparities are persistent across racial/ethnic groups for older Americans despite the fact that the differences between groups typically diminish when socioeconomic, health-related, and behavioral factors are considered in the models. These and other factors discussed above deserve greater attention in future research about oral health disparities for all minorities. Also, longitudinal studies are needed to examine the impact of SES, lack of community resources, cumulative disadvantages, and cultural values and beliefs on oral health across all racial/ethnic groups. These disparities could reflect a historical lack of access to dental care in racial/ethnic minorities, lifetime dietary habits, lifetime prevalence of negative health behaviors, and racial/ ethnic differences in oral health beliefs. The decreasing rates of edentulism among minorities have resulted in more teeth at risk for decay or loss, and, subsequently, the need for access to dental treatment and dental care facilities in minority neighborhoods. Our study suggests that reducing racial/ethnic oral health disparities requires multiple clinical approaches. First, it is important to improve access for dental care for minority elders. Second, it is critical to increase older adults' knowledge of the importance of oral health, including the linkage between oral health and systemic medical conditions, oral hygiene, and preventive dental care services. Third, programs are needed to improve individuals' overall health behaviors perhaps through encouraging positive behaviors that can help older Americans retain their natural teeth and maintain good oral health later in life. Fourth, develop and improve culturally competent services for minority communities by recruiting more underrepresented minorities to the dental professions, and enrich dental education curriculum (28).

\section{Acknowledgments}

This study is funded by the National Institute of Dental and Craniofacial Research (NIDCR) (1 R21 DE019518-01). We would like to thank the staff from the Dental, Oral and Craniofacial Data Resource Center at the Centers for Disease Control and Prevention, and NIDCR for their technical support.

\section{References}

1. Day JC. Population projections of the United States by age, sex, race and Hispanic origin: 1995-2050. Current population reports, p25-1130 (online). [cited 2009 July 31]. Available from: http://www.census.gov/prod/1/pop/p25-1130.pdf.
2. Oral Health in America. A report of the Surgeon General. Rockville, MD: National Institute of Dental and Craniofacial Research; 2000.

3. Dye BA, Tan S, Smith V et al. Trends in oral health status: United States, 1988-1994 and 1999-2004. National Center for Health Statistics. Vital Health Stat. 2007;11(248):1-92.

4. Watson MR, Brown LJ. The oral health of U.S. Hispanics: evaluating their needs and their use of dental services. J Am Dent Assoc. 1995;126:789-95.

5. Randolph WM, Ostir GV, Markides KS. Prevalence of tooth loss and dental service use in older Mexican Americans. J Am Geriatr Soc. 2001;49:585-9.

6. Quandt SA, Chen H, Bell RA et al. Disparities in oral health status between older adults in a multiethnic rural community: the rural nutrition and oral health study. J Am Geriatr Soc. 2009;57:1369-75.

7. Kiyak HA, Kamoh A, Persson RE et al. Ethnicity and oral health in community-dwelling older adults. Gen Dent. 2002;50:513-8.

8. Craig RG, Boylan R, Yip J et al. Prevalence and risk indicators for destructive periodontal diseases in three urban American minority populations. J Clin Periodontol. 2001;28:524-35.

9. Borrell LN, Burt BA, Neighbors HW et al. Social factors and periodontitis in an older population. Am J Public Health. 2004;94:748-54.

10. Hudson K, Stockard J, Ramberg Z. The impact of socioeconomic status and race-ethnicity on dental health. Sociol Perspect. 2007;50:7-25.

11. National Center for Health Statistics. National Health and Nutrition Examination Survey (NHANES) overview. Centers for Disease Control and Prevention; 2003 Hyattsville, MD. [cited 2009 Aug 13]. Available from: http://www.cdc.gov/ nchs/data/nhanes/nhanes_03_04/overviewbrochure_ 0304.pdf.

12. Clogg CC, Petkova E, Haritou A. Statistical methods for comparing regression coefficients between models. AJS. 1995;100:1261-93.

13. National Center for Health Statistics. National Health and Nutrition Examination Survey (NHANES) analytic and reporting guidelines. 2006 [cited 2010 Nov 10]. Available from: http://www.cdc.gov/nchs/nhanes/nhanes2003-2004/ analytical_guidelines.htm.

14. Schafter JL. Analysis of incomplete multivariate data. London: Chapman \& Hall; 1997.

15. Stata Corporation. Multiple-imputation reference manual. College Station, TX: Stata Press; 2009.

16. Bramlett MD, Soobader MJ, Fisher-Owens SA et al. Assessing a multilevel model of young children's oral health with national survey data. Community Dent Oral Epidemiol. 2010;38:287-98.

17. Allison P. Logistic regression using the SAS system: theory and application. Cary, NC: SAS Institute; 1999.

18. Cunha-Cruz J, Hujoel PP, Nadanovsky P. Secular trends in socio-economic disparities in edentulism: USA, 1972-2001. J Dent Res. 2007;86:131-6. 
19. Zabos GP, Northridge ME, Ro MJ et al. Lack of oral health care for adults in Harlem: a hidden crisis. Am J Public Health. 2002;92:49-52.

20. Davidson PL, Andersen RM. Determinants of dental care utilization for diverse ethnic and age groups. Adv Dent Res. 1997;11:254-62.

21. Manski RJ, Magder L. Demographic and socioeconomic predictors of dental care utilization. J Am Dent Assoc. 1998;129:195-7.

22. Doty HE, Weech-Maldonado R. Racial/ethnic disparities in adult preventive dental care use. J Health Care Poor Underserved. 2003;14:516-34.

23. Nakazono TT, Davidson PL, Andersen RM. Oral health beliefs in diverse populations. Adv Dent Res. 1997;11:235-44.

24. You Z, Cushman M, Jenny NS et al. Tooth loss, systemic inflammation, and prevalent stroke among participants in the reasons for geographic and racial differences in stroke (REGARDS) study. Atherosclerosis. 2009;203:615-9.

25. Wu T, Trevisan M, Genco RJ, Dorn JP, Falkner KL, Sempos CT. Periodontal disease and risk of cerebrovascular disease: the first national health and nutrition examination survey and its follow-up study. Arch Intern Med. 2000;160(18): 2749-55.

26. Holm-Pedersen P, Schultz-Larsen K, Christiansen N, Avlund $\mathrm{K}$. Tooth loss and subsequent disability and mortality in old age. J Am Geriatr Soc. 2008;56:429-35.

27. Bzostek S, Goldman N, Pebley A. Why do Hispanics in the USA report poor health? Soc Sci Med. 2007;65:990-1003.

28. Lopez N, Wadenya R, Berthold P. Effective recruitment and retention strategies for underrepresented minority students: perspectives from dental students. J Dent Educ. 2003;67: 1107-12. 